\title{
Pemberdayaan Masyarakat Melalui Gerakan Serentak PHBS Pada Tatanan Rumah Tangga
}

\author{
Nurul Hidayah*, Marwan, Dhian Luluh Rahmawati \\ Akademi Keperawatan Pemerintah Ngawi, Indonesia \\ * nurulridlo@gmail.com
}

\begin{abstract}
ABSTRAK
Perilaku hidup bersih sehat (PHBS) dalam tatanan rumah tangga merupakan kegiatan yang dilakukan oleh setiap anggota keluarga untuk berpartisipasi aktif dalam mencegah penyakit, dan meningkatkan kesehatan keluarganya yang dilakukan atas dasar kesadaran sendiri. Salah satu indikator PHBS pada tatanan rumah tangga adalah penggunakan jamban sehat pada keluarga. Pengabdian ini bertujuan untuk mengidentifikasi pemberdayaan masyarakat melalui gerakan serentak PHBS pada tatanan rumah tangga di Dusun Cung Belut, Desa Semen Kecamatan Paron Kabupaten Ngawi. Metode yang digunakan adalah penyuluhan jamban sehat, stimulasi jamban sehat sederhana, dan pembentukan kader STBM, dengan populasi target adalah warga Dusun Cung Belut sebanyak 142 somah. Setelah diberikan penyuluhan jamban sehat pengetahuan masyarakat tentang jamban sehat meningkat sebesar $75 \%$, warga yang bersedia membuat jamban sehat dengan konsep stimulan sebanyak 6 somah, terbentuk kader cilik STBM yang beranggotakan 15 anak. Kesimpulan: Gerakan serentak PHBS pada tatanan rumah tangga efektif untuk mengatasi masalah PHBS di Dusun Cung Belut Desa Semen Kecamatan Paron Kabupaten Ngawi.
\end{abstract}

Kata Kunci: PHBS, Tatanan Rumah Tangga, Dusun Cung Belut

\section{PENDAHULUAN}

Perilaku hidup bersih sehat (PHBS) pada tatanan rumah tangga merupakan tindakan mandiri anggota keluarga untuk menolong dirinya sendiri dalam masalah kesehatan yang dilakukan atas kesadaran pribadi sehingga mampu berperan aktif dalam masyarakat. Tujuan PHBS dalam tatanan rumah tangga ini untuk mencegah serta menanggulangi masalah kesehatan dan lingkungan, masalah kesehatan ibu dan anak (KIA), keluarga berencana $(\mathrm{KB})$, gizi keluarga, farmasi dan pemeliharaan kesehatan keluarga secara umum. Melalui gerakan PHBS ini diharapkan akan terbentuk agen-agen pembaharu kesehatan yang akan merubah perilaku kesehatan yang kurang tepat menjadi lebih baik pada tingkat keluarga, yang nantinya berdampak pada kesehatan masyarakat setempat atau dengan kata lain terbentuk rekayasa sosial pada masyarakat tersebut (Kemenkes RI, 2011). Keluarga yang sehat menjadi aset pembangunan bangsa, oleh karena itu kegiatan pemberdayaan PHBS dapat dimulai dari tingkat keluarga. Selain itu adanya perbedaan masa rawan terjangkit suatu penyakit pada setiap anggota keluarga menjadi faktor 


\section{Journal of Community Engagement in Health}

http://jceh.org

ISSN: 2620-3758 (print); 2620-3766 (online)

https://doi.org/10.30994/jceh.v3i2.47

Vol.3 No.2. Sep 2020. Page.123-128

pendukung untuk adanya kegiatan pemerdayaan PHBS dalam tatanan rumah tangga (Nurhajati, 2019).

Data Profil Kesehatan Provinsi Jawa Timur menyebutkan jumlah penduduk jawa timur yang paling banyak melakukan PHBS adalah Surabaya $(75,1 \%)$, sedangkan perilaku PHBS di Kabupaten Ngawi sebanyak (42,5\%) (Dinkes Provinsi, 2017). Berdasarkan penelitian Hidayah, (2019) didapatkan data PHBS pada tatanan keluarga di Dusun Cung Belut diperoleh hasil proses persalinan sebagian besar nornal dan ditolong bidan 278 (59,5\%), anggota keluarga belum mendapatkan ASI Eksklusif $324(69,4 \%)$, anggota keluarga belum menimbangkan bayi dan balitanya secara rutin 298 (64\%), kebiasaan mencuci tangan menggunakan sabun dan air mengalir $170(36,4 \%)$, menggunakan sumber air bersih untuk kegiatan sehari-hari 142 (100\%), memiliki jamban septictank sebanyak 84 (59\%), tempat penampungan air bebas jentik 92 KK (64\%), mengonsumsi sayur dan buah kurang dari 3 kali setiap minggu 112 (78,9\%), aktifitas fisik seminggu sekali 78 (55\%), kebiasaan merokok di dalam rumah 140 (98,6\%). Masih minimnya PHBS pada keluarga juga dapat dilihat di daerah Samir, dari 10 indikator PHBS ada 7 indikator telah memenuhi target, sedangkan 3 indikator dibawah target (Nurhajati, 2019). PHBS yang baik dalam keluarga juga berpengaruh pada status gizi keluarga, hal ini sesuai penelitian Jayanti (2011), menyatakan PHBS dalam lingkungan keluarga berkorelasi positif dengan status gizi.

Indikator yang dipakai dalam PHBS pada tatanan rumah tangga adalah proses persalinan yang ditolong oleh tenaga kesehatan, pemberian ASI eksklusif, menimbang bayi dan balita secara berkala, mencuci tangan dengan sabun dan air bersih, menggunakan air bersih, menggunakan jamban sehat, memberantas jentik nyamuk, mengkonsumsi buah dan sayur, melakukan aktivitas fisik setiap hari, dan tidak merokok di dalam rumah (Kemenkes RI, 2017). Dengan menerapkan indikator PHBS tersebut diharapkan dapat menciptakan keluarga sehat dan meminimalisir masalah kesehatan. Upaya yang dilakukan agar tercipta PHBS dalam tatanan rumah tangga melalui edukasi kepada anggota keluarga dan pemberdayaan anggota keluarga dengan tujuan mampu mengenal masalah kesehatan untuk memperbaiki pola dan gaya hidup agar lebih sehat (Kemenkes RI, 2017). Berdasarkan uraian diatas penulis tertarik melakukan kegiatan pengabdian masyarakat dengan judul Pemberdayaan Masyarakat Melalui "Gertak PHBS Pada Tatanan Rumah Tangga" Di Dusun Cung Belut, Desa Semen Kecamatan Paron Kabupaten Ngawi.

\section{TUJUAN}

Mengidentifikasi Upaya Mewujudkan Desa ODF Melalui Gerakan Serentak PHBS Pada Tatanan Rumah Tangga” Di Dusun Cung Belut, Desa Semen Kecamatan Paron Kabupaten Ngawi.

\section{METODE}

Metode dalam pemberdayaan masyarakat ini adalah dengan menganalisis indikator PHBS pada tatanan keluarga khususnya pada pemakaian jamban keluarga yag memenuhi syarat kesehatan. Kegiatan yang diprogramkan adalah: Penyuluhan jamban sehat dan stop BABs, stimulan jamban sehat sederhana, dan pelatihan kader cilik dengan melibatkan langsung masyarakat pada setiap program yang direncanakan.

Populasi dalam kegiatan ini adalah keluarga yang tinggal di Dusun Cung Belut Desa Semen Kecamatan Paron Kabupaten Ngawi, sebanyak 142 somah.

Pengabdian masyarakat ini dilakukan pada Februari-Maret 2019 


\section{Journal of Community Engagement in Health}

http://jceh.org

ISSN: 2620-3758 (print); 2620-3766 (online)

https://doi.org/10.30994/jceh.v3i2.47

Vol.3 No.2. Sep 2020. Page.123-128

\section{HASIL DAN PEMBAHASAN}

Data demografi

Jumlah penduduk Dusun Cung Belut pada tahun 2019 adalah: 467 jiwa, dengan penduduk laki-laki sebesar 232 jiwa, perempuan 235 jiwa. Distribusi penduduk berdasarkan kelompok usia: Balita 35 orang, anak 56 orang, remaja 68 orang, dewasa 225 orang, dan Lansia 83 orang. Terdapat 158 KK dan 142 soma.

\section{Pekerjaan Dan Pendapatan}

Sebagian warga bekerja sebagai petani sebanyak 179 orang, buruh tani 80 orang, peternak ikan 45 orang, pedagang 30 orang, swasta 15 orang, PNS 2 orang, dan tidak bekerja 7 orang. Rerata pendapatan penduduk setiap bulan antara Rp 500.000-Rp1.000.000,-.

\section{Perilaku kepemilikan jamban pada tatanan kelarga}

Beberapa perilaku tentang kepemilikan dan penggunaan jamban keluarga dapat dilihat pada tabel 1

Tabel 1: perilaku kepemilikan jamban pada tatanan keluarga

\begin{tabular}{|l|l|l|l|}
\hline $\begin{array}{l}\mathbf{N} \\
\mathbf{0}\end{array}$ & Kepemilikan jamban & Frekuensi somah & \% \\
\hline $\mathbf{1}$ & Jamban sehat & & \\
\hline & Jamban Septictank & 84 & 59 \\
\hline $\mathbf{2}$ & Jamban tidak sehat & & \\
\hline & Jamban kolam lele & 22 & 16 \\
\hline & WC cemplung & 17 & 12 \\
\hline & Numpang tetangga & 13 & 9 \\
\hline & Disungai & 2 & 1 \\
\hline & Tanah/gali & 4 & 3 \\
\hline & Total & $\mathbf{1 4 2}$ & $\mathbf{1 0 0}$ \\
\hline
\end{tabular}

\section{Sumber :Data Primer}

Dari tabel diatas dapat disimpukan sebagian besar warga sudah mempunyai jamban dengan septictank sebesar 44 somah, akan tetapi masih terdapat warga yang mempunyai kebiasaan BAB tidak sesuai syarat kesehatan, diantaranya: di kolam lele 22 somah, WC cemplung terbuka 17 somah, di sungai 2 somah dan di tanah dengan cara digali 4 somah. Hal ini tentu dapat memberikan dampak negatif pada kesehatan, mengingat tinja merupakan salah satu media penularan penyakit. Kondisi ini perlu mendapatkan penanganan segera. Kegiatan yang diprogramkan untuk menangani masalah jamban dengan dilakukan penyuluhan tentang jamban sehat dan STOP BABs serta peberian stimulan jamban sehat pada warga.

\section{Kegiatan penyuluhan tentang STOP BABs dan jamban sehat}

Kegiatan penguluhan ini ditujukan meningkakan pengetahuan warga tentang penggunaan jamban sehat. Kegiatan ini dilaksanakan menjadi beberapa tahap, antara lain: persiapan, pelasanaan dan evaluasi. Tahap persiapan meliputi kegiatan koordinasi dengan perangkat Desa seperti Kades, Kasun, Ketua RT/RW dan kader untuk mensosialisasikan kegiatan penyuluhan yang akan dilakukan pada tanggal 26 Februari 2019. Tema dari penyuluhan ini adalah "STOP Buang Air Besar di sembarang Tempat dan jamban sehat", jumlah warga yang diundang $42 \mathrm{KK}$ dengan jamban di kolam lele. Pada tahap pelaksanaan kegiaatan dilakukan dengan cara merealisasikan rencana penyuluhan pada tanggal 26 Februari 2019 yang bertempat di rumah salah satu warga Dusun Cung belut yaitu bpk Slamet. Pada kegiatan ini kami mendapatkan dukungan penuh dari perangkat Desa dan 


\section{Journal of Community Engagement in Health}

warga, hal ini dapat dilihat dari pelaksanaan kegiatan yang kami lakukan. Warga membantu menyiapkan tempat, tikar, konsumsi (snack dan air mineral). Dukungan lain dari warga juga diperlihatkan dengan warga datang terlebih dahulu sebelum acara dimulai. Antusiasme warga juga sangat tinggi, hal ini dilihat dari banyaknya pertanyaan yang diungkapkan saat penyuluhan berlangsung. Pada pelaksanaan kegiatan ini kami menggunakan metode ceramah, diskusi dan pemutaran video, tentang kebiasaan BABs dan jamban sehat. Evaluasi dari kegiatan ini diperoleh hasil pemahaman audiens tentang STOP BABs dan jamban sehat meningkat sebesar $75 \%$. Hal ini dapat dilihat dari jumlah soal yang dapat dijawab dengan benar oleh audiens tentang STOP BABs dan jamban sehat. Sebanyak 6 audiens juga bersedia mengikuti anjuran untuk merefungsi jamban kolam lelenya menjadi jamban sehat sederhanan dengan teknik stimulan setelah mengikuti kegiatan penyuluhan. Pemilihan metode ini mengacu pada penelitian Hidayah dan Marwan (2018) yang menyatakan bahwa metode pemberdayaan masyarakat dengan modifikasi teknik penyuluhan dan stimulan terbukti efektif untuk merubah perilaku warga Dusun Gebang Sewu dengan kebiasaan BAB di kolam Lele, hal ini dapat dilihat dari $23 \mathrm{KK}$ yang beralih ke Jamban sehat sederhana melalui teknik stimulan, terbentuknya Perdes dan Kader Cilik STBM

\section{Kegiatan pemberian stimulan jamban sehat sederhana}

Kegiatan pemberian stimulan jamban sehat ini merupakan salah satu upaya nyata untuk mengentaskan masalah BABs di Dusun Cung Belut. Mendasar pada hasil evaluasi kegiatan penyuluhan tentang STOP BABs pada tanggal 26 Februari 2019 dari 24 Somah yang belum mempunyai jamban sehat, 6 somah akhirnya sepakat membuat jamban sehat dengan menggunakan tehnik stimulan, dimana sebagain dana pembuatan jamban dibantu dari dana stimulan dan lainnya berasal dari warga. Dengan demikian warga juga mempunyai keinginan berusaha untuk memiliki jamban sehat di rumahnya. Jenis jamban yang dibangun adalan jamban sehat sederhana. Menurut Proverawati (2012) syarat jamban sehat adalah: tidak mencemari sumber air minum (jarak antara sumber air minum dengan lubang penampungan minimal 10 meter), tidak berbau, kotoran tidak dapat dijamah oleh hewan, tidak mencemari tanah sekitar, mudah di bersihkan, terdapat bangunan atas jamban (dinding dan/atau atap), terdapat lubang ventilasi yang cukup kemudian lantai yang kedap air dan luas ruangan memadai serta tersedianya air, sabun dan alat pembersih. Setiap unit septictang jamban sehat sederhana membutuhkan dana sebesar Rp 550.000 .00 sedangkan dana stimulan untuk setiap unit sebesar Rp 160.000.00 , sehingga warga menanggung kekurangan sebesar Rp 390.000.00. Kegiatan ini dilakukan pada tanggal, 3-18 Maret 2019 dengan menggunakan teknik gotong-royong. Evaluasi kegiatan ini dilakukan pada tanggal 25 Maret 2019 dan diperoleh hasil, dari 6 jamban yang dibangun sudah dimanfaatkan semua oleh anggota keluaga, dan jamban dalam kondisi terawat.

\section{Pelatihan kader cilik STBM}

Pelatihan perawat cilik STBM ditujukan untuk meningkatkan pemahaman anak-anak tentang PHBS dalam tatanan keluarga. Selain itu anak-anak diharapkan menjadi role model bagi keluarga untuk senantiasa menjaga PHBS dalam tatanan keluarga selepas kegiaatan pengabdian ini berakhir. Pada kegiatan pelatihan ini diberikan materi tentang larangan BABs, cara mencuci tangan yang benar, penggunaan air bersih, cara pengelolaan sampah keluarga, dan pengelolaan limbah keluarga. Kegiatan ini dilakukan pada tanggal 20 Maret 2019. Metode yang digunakan adalah ceramah, audiovisual dan demonstrasi. Diakhir kegiatan dilakukan evaluasi dengan memberikan quesionare berisi pertanyaan seputar 


\section{Journal of Community Engagement in Health}

http://jceh.org

ISSN: 2620-3758 (print); 2620-3766 (online)

https://doi.org/10.30994/jceh.v3i2.47

Vol.3 No.2. Sep 2020. Page.123-128

materi yang telah diberikan. Sebagai bentuk penghargaan dan supaya peserta pelatihan termotivasi untuk mengikuti pelatihan, peserta pelatihan diberi PIN Perawat cilik STBM dan sertifikat. Rencana tindak lanjut untuk para perawat cilik STBM ini dengan melakukan koordinasi dengan petugas Puskesmas bidang kesehatan lingkungan, untuk mendapatkan pembinaan lebih lanjut.

\section{KESIMPULAN}

Pemberdayaan masyarakat melalui kegiatan gertak PHBS pada tatanan rumah tangga dengan menggunakan metode penyuluhan, stimulan jamban sehat, dan pembentukan perawat cilik STBM terbukti efektif untuk merubah perilaku warga Cung Belut dari kebiasaan $\mathrm{BAB}$ yang tidak sesui dengan kesehatan, hal ini dapat dilihat $6 \mathrm{KK}$ yang beralih ke Jamban sehat sederhana melalui teknik stimulan. Di Dusun Cung Belut juga telah terbentuk Kader Cilik STBM yang akan menjadi role model pada keluarganya.

\section{UCAPAN TERIMAKASIH}

Ucapan terimakasih disampaikan kepada Kepala Desa Semen, kepala Dusun Cung Belut, ibu-ibu kader dan warga Dusun Cung Belut Wilayah Puskesmas Teguhan yang telah membantu kegiatan terlaksananya program pengabdian masyarakat.

\section{DAFTAR PUSTAKA}

Dinas Kesehatan Provinsi Jatim, 2017. Buku Profil kesehatan provinsi jawa timur, tersedia dalam: www.depkes.go.id/resources/.../profil/PROFIL...PROVINSI_2017/15_Jatim_2017.p $\underline{\mathrm{df}}$

Hidayah, N., Marwan., 2018. Upaya pemberdayaan masyarakat melalui refungsi jamban kolam lele menjadi jamban sehat dalam rangka menuju desa ODF (Open Defecation Free). Jurnal Pengabdian Masyarakat Kesehatan : Vol 4(2) Tersedia dalam http://journal.stikespemkabjombang.ac.id/index.php/jpm/article/view/178

Hidayah, N., 2019. Perilaku hidup bersih sehat pada tatanan rumah tangga di dusun cung belut, desa semen kecamatan paron, kabupaten ngawi, Jurnal Warta Bhakti Husada $\begin{array}{lllll}\text { Mulia: } & \text { Vol } & 6 & (1) . & \text { Tersedia dalam }\end{array}$ http://jurnal.bhmm.ac.id/index.php/jurkes/article/view/118

Jayanti, L.D., Effendi, Y.H., Sukandar, D., 2011. Perilaku hidup bersih dan sehat (phbs) serta perilaku gizi seimbang ibu kaitannya dengan status gizi dan kesehatan balita di kabupaten bojonegoro, jawa timur, Jurnal Gizi Dan Pangan. Vol 6 (3). Tersedia dalam: http://journal.ipb.ac.id/index.php/jgizipangan/article/view/6130

Kemenkes RI, 2017, Program Indonesia Sehat dengan Pendekatan Keluarga, tersedia dalam: http://www.depkes.go.id/article/view/17070700004/program-indonesia-sehatdengan-pendekatan-keluarga.html

Kemenkes RI, 2011, PHBS. Tersedia dalam: http://promkes.kemkes.go.id/phbs

Nurhajati, N., 2019. Perilaku hidup bersih dan sehat (phbs) masyarakat desa samir dalam meningkatkan kesehatan masyarakat, Publiciana, Vol 8(1) http://www.jurnalunita.org/index.php/publiciana/article/view/43 
Journal of Community Engagement in Health

http://jceh.org

https://doi.org/10.30994/jceh.v3i2.47

ISSN: 2620-3758 (print); 2620-3766 (online)

Vol.3 No.2. Sep 2020. Page.123-128

Proverawati A; Rahmawati E., 2012. Perilaku Hidup Bersih dan Sehat (PHBS). Yogyakarta: Nuha Medika 